\title{
Profile of Chronic Mental Disorder Patients with or without Suicide Ideation in the Psychiatric Ward of Dr. Soetomo General Hospital, Surabaya
}

\author{
Khoirun Nada Salsabila ${ }^{1}$, Khairina ${ }^{2^{*}}$, Lilik Djuari $^{3}$
}

${ }^{1}$ Faculty of Medicine, Universitas Airlangga, Surabaya, Indonesia.

2Department of Psychiatry, Faculty of Medicine, Universitas Airlangga/Dr. Soetomo General Hospital, Surabaya, Indonesia. ${ }^{3}$ Department of Public Health and Preventive Medicine, Universitas Airlangga, Surabaya, Indonesia.

Introduction: Risk factors for suicide ideation or suicide are the history of mental illness, family history with suicide or depression, and having suicide attempts. This study aimed to determine patients with mental disorder profiles that had suicide ideation and never had suicide ideation. This study also aimed to identify the intensity of suicide idea and history of suicide attempts at a subject that had suicide ideation.

Methods: This was a descriptive observational study. This study was conducted using C-SSRS questionnaires and some additional interviews with chronic mental disorder patients in the Psychiatric Ward, Dr. Soetomo General Hospital, Surabaya.

Results: Total patients that had suicide ideation were 11 patients, consisted of 8 patients with schizophrenia, and 2 patients with bipolar disorder. The mean length of illness was 16.55 years, GAF Scale when suicide ideation appeared was at range 40-31 until 60-51. GAF Scale got better in range 60-51 until 80-71, mostly in teenagers and adults when suicide ideation appeared, primarily women. Many of them were unemployed, had lower income, did not have income, and were noncollege graduates. The total subjects that never had suicidal ideation were 23 patients, 2 of them with depression, mean age of illness onset was 12.04 years old, the balance between women and men, some of them were sellers and worked in a private field, with income range between 2 until 5-6 million, and few of them were college graduates.

Conclusion: Suicide ideation was mostly found in some subjects with younger age, had longer length of illness, had lower GAF Scale, primarily women, unemployed, had lower income, and had lower education.

\section{*Correspondence: rina250515@gmail.com}

JUXTA: Jurnal Ilmiah Mahasiswa Kedokteran Universitas Airlangga

p-ISSN: 1907-3623; e-ISSN: 2684-9453

DOI: 10.20473/juxta.V12I22021.48-53

Open access under Creative Commons Attribution-ShareAlike 4.0 International License (CC-BY-SA)

\section{ARTICLE INFO}

\section{Article history:}

Received 6 November 2020

Received in revised form 23 November 2020

Accepted 3 December 2020

Available online 31 August 2021

\section{Keywords:}

C-SSRS,

Chronic mental disorder,

Suicide,

Suicide ideation. 


\section{Introduction}

Mental health is still a problem that has not been resolved well, especially in Indonesia. According to the data from the WHO (2016), there are 35 million people in Indonesia suffer from depression, 60 million people with bipolar, 21 million people with schizophrenia, and 47.5 million people with dementia. ${ }^{1}$

Psychiatric disorders can include severe mental disorders and emotional disorders. Severe mental disorders are the disruption of the ability to assess reality, whereas emotional disorder is a term for distress characterized by a person's psychological change. The highest prevalence of severe mental disorders (psychosis and schizophrenia) is in Yogyakarta and Aceh, with 2.7\%. East Java also has a reasonably high prevalence, with $2.2 \%$. The prevalence of severe mental disorders in Indonesia is 1.7 per mile. The prevalence of emotional, mental disorders with nationally aged criteria over 15 years old is $6.0 \%$, or 37,728 people from the subject of analysis. The region with the highest prevalence is Central Sulawesi with $11.6 \%$, and the prevalence in East Java reaches $6.5 \% .^{2}$

Psychiatric disorders can lead to something more serious, such as suicide, if not properly handled. In Indonesia, the mortality rate of suicide is 2.9 per 100,000 or below the regional average of Southeast Asia, which reaches 12.9 per 100,000 inhabitants and is still below the global average with 10.7 per 100,000 population. Europe has an average of the highest mortality rate reaching 14.1 per 100,000 inhabitants. However, in Southeast Asia, Thailand has the highest mortality rate of 16.0 per 100,000 inhabitants. $^{3}$

The risk factors of suicide include psychiatric disorders, family history of suicide or depression, and the history of suicide experiments. A source states that $90 \%$ of suicidal cases occur due to mental disorders. Approximately $2-15 \%$ of patients with severe depression committed suicide. In addition to depression, $3-20 \%$ of bipolar sufferers and $6-15 \%$ of schizophrenic patients also committed suicide. ${ }^{4}$ Severe depression has twenty times more chances of suicide. ${ }^{5}$

Although the suicide rate is not high enough, it still needs special attention because the number of mental disorders in Indonesia is still relatively high, including East Java. Some studies reveal that a person with chronic psychiatric disorders has a greater chance of committing suicide. Furthermore, this research aimed to examine patients with mental disorder's profile that had suicide ideation and never had suicide ideation and identify the intensity of suicide idea and history of suicide attempts at patients that had suicide ideation in the Psychiatric Ward, Dr. Soetomo General Hospital, Surabaya.

\section{Methods}

This study used the design of descriptive observational research. A descriptive type of research because it describes the profile of chronic psychiatric disease patients who have had a suicide idea or have had a suicide idea. Observational research is a study that does not provide any intervention in patients, so it focuses on observation alone. The research location was the Psychiatric Ward, Dr. Soetomo General Hospital, Surabaya. The research was conducted from March 2018 to June 2019.

The research population of this study was patients with chronic psychiatric disorders in the Psychiatric Ward, Dr. Soetomo General Hospital, Surabaya. The minimum number of samples required in this study was 31 people, but we obtained 35 people as a backup if there was a dropout or invalid data. The sampling technique used nonrandom sampling, which is a type of quota sampling. The quota sampling is done with the specified quota and can be terminated if it meets the sample quota.

The patients criteria for this study were patients who had chronic psychiatric disorders, including schizophrenia, schizoaffective disorders, bipolar affective disorder, and depression. Patients could be cooperative, communicate well using Bahasa Indonesia, and be competent to participate in this research. The patients were in a conducive condition and aged 16-65 years old, and did not refuse to engage in this research.

This research used questionnaires as an instrument. The questionnaire is used based on the Columbia Suicide Severity Rating Scale (C-SSRS). C-SSRS can be used to determine the presence of suicidal ideation and suicidal actions. The study also needed an interview of additional questions taken from several questions in the Practice Guidelines for The Assessment and Treatment of Patients with Suicidal Behaviors. Besides that, this research also required medical records and patient data. Medical records were used to determine the diagnosis, length of pain, and value of the patients GAF Scale. Patients data were used to determine the patients' profile of age, gender, religion, ethnicity, education, occupation, and income.

Data processing technique was carried out using SPSS applications. The analysis of data was conducted using descriptive statistics. It consists of frequency, descriptive, and cross-tabs that could compare two results of different variables. 


\section{Results}

Table 1. The distribution of chronic psychiatric disorders patients who had suicide idea and never had a suicide idea

\begin{tabular}{lcc}
\hline Idea & Frequency & Total (\%) \\
\hline Yes & 11 & 31.4 \\
No & 24 & 68.6 \\
\hline Total & 35 & 100 \\
\hline
\end{tabular}

Table 1 shows that there are patients with chronic psychiatric disorders who have an idea of suicide as much as 11 persons or $31.4 \%$ and who never have a suicide idea of 24 persons or $68.6 \%$.

Table 2. Length of illness of chronic psychiatric disorders patients who had suicide ideas and never had a suicide idea

\begin{tabular}{lcc}
\hline Length of Illness & \multicolumn{2}{c}{ Idea } \\
\cline { 2 - 3 } & Yes & No \\
\hline Mean & 16.55 years & 12.04 \\
& & years \\
Standard of Deviation & 12.941 & 8.307 \\
Minimum Value & 2 years & 2 years \\
Maximum Value & 35 years & 30 years \\
\hline
\end{tabular}

Table 2 shows the average length of the illness and the standard of its deviation. Patients who had the idea of suicide have an average length of illness 16.55 years with a minimum value of 2 years and a maximum value of 35 years, and a standard deviation of 12.941 . Patients who never had a suicide idea have an average length of illness for 12.04 years, with a minimum value of 2 years and a maximum value of 30 years, as well as a standard deviation of 8.307 .

Table 3. Profile of chronic psychiatric disorders patients who had suicide ideas and never had a suicide idea

\begin{tabular}{|c|c|c|c|c|}
\hline \multirow[t]{2}{*}{ Profile } & \multicolumn{2}{|c|}{ Idea } & \multirow[t]{2}{*}{ Frequency } & \multirow[t]{2}{*}{ Total (\%) } \\
\hline & Yes & No & & \\
\hline \multicolumn{5}{|l|}{ Diagnosis } \\
\hline Schizophrenia & 8 & 21 & 29 & 82.9 \\
\hline Schizoaffective Disorder & 1 & 1 & 2 & 5.7 \\
\hline Bipolar Affective Disorder & 2 & 0 & 2 & 5.7 \\
\hline Depression & 0 & 2 & 2 & 5.7 \\
\hline \multicolumn{5}{|l|}{ Current GAF Scale } \\
\hline $50-41$ & 0 & 1 & 1 & 2.9 \\
\hline $60-51$ & 5 & 6 & 11 & 31.4 \\
\hline $70-61$ & 2 & 9 & 11 & 31.4 \\
\hline $80-71$ & 4 & 8 & 12 & 34.3 \\
\hline \multicolumn{5}{|l|}{ Current Age Groups } \\
\hline Adolescent & 0 & 0 & 0 & 0 \\
\hline Late Adolescent & 2 & 2 & 4 & 11.4 \\
\hline Young Adult & 1 & 3 & 4 & 11.4 \\
\hline Adult & 4 & 8 & 12 & 34.3 \\
\hline Senior & 4 & 10 & 14 & 40.0 \\
\hline Old & 0 & 1 & 1 & 2.9 \\
\hline \multicolumn{5}{|l|}{ Gender } \\
\hline Male & 5 & 12 & 17 & 48.6 \\
\hline Female & 6 & 12 & 18 & 51.4 \\
\hline \multicolumn{5}{|l|}{ Jobs } \\
\hline Civil Servant & 1 & 0 & 1 & 2.9 \\
\hline Trade & 0 & 3 & 3 & 8.6 \\
\hline Labor & 0 & 1 & 1 & 2.9 \\
\hline Private Field & 4 & 5 & 9 & 25.7 \\
\hline Helping Family & 1 & 7 & 8 & 22.9 \\
\hline Jobless & 5 & 8 & 13 & 37.1 \\
\hline \multicolumn{5}{|l|}{ Income } \\
\hline$<2.5$ million IDR & 4 & 5 & 9 & 25.7 \\
\hline $2.5-6$ million IDR & 2 & 5 & 7 & 20.0 \\
\hline No Income & 5 & 14 & 19 & 54.3 \\
\hline \multicolumn{5}{|l|}{ Education } \\
\hline Elementary & 1 & 2 & 3 & 8.6 \\
\hline Junior High School & 2 & 4 & 6 & 17.1 \\
\hline Senior High School & 6 & 15 & 21 & 60.0 \\
\hline Diploma degree & 1 & 1 & 2 & 5.7 \\
\hline Bachelor degree & 1 & 2 & 3 & 8.6 \\
\hline
\end{tabular}


Table 3 is a complete result of the patients' profile who once had an idea of suicide and never had any idea of suicide in the Psychiatric Ward, Dr. Soetomo Academic Hospital, Surabaya. It consists of a diagnosis, current GAF Scale, age group, gender, occupation, income, and education. The most number of diagnoses to be schizophrenia. Bipolar occurred in only two people but once had a suicide idea, while the depressive episode was only two people and without any suicide. Current GAF Scale patients are almost entirely more than 50-41. The age group is currently dominated by adulthood and the elderly and pretty much has ever had a suicide idea. There are almost equal numbers of men and women who had suicidal ideation or never had suicidal ideation. Mostly, the results found that the patients did not have a job, but quite a few had a job in the private sector. The majority of patients had a reduction of less than 2.5 million per month, not even earning at all. The average patient had a history of education to high school, and some had a lower education history.

Table 4. Additional profiles of chronic psychiatric disorders patients who have had suicidal ideation

\begin{tabular}{lcc}
\hline Profile & Frequency & Total (\%) \\
\hline GAF Scale & & \\
$40-31$ & 2 & 18.2 \\
$50-41$ & 2 & 18.2 \\
$60-51$ & 5 & 45.5 \\
No Data & 2 & 18.2
\end{tabular}

\section{Age Groups}

\begin{tabular}{lcc} 
Adolescent & 1 & 9.1 \\
Late Adolescent & 4 & 36.4 \\
Young Adult & 1 & 9.1 \\
Adult & 4 & 36.4 \\
Senior & 1 & 9.1 \\
\hline
\end{tabular}

In Table 4, there are additional profiles on GAF Scale and age groups on psychosis with chronic psychiatric disorders when they have suicidal ideation. GAF Scale at the time of the suicide idea was quite low, which was between 31-40 to $60-51$. The most age groups when having suicidal ideation were in late adolescent and adult.

Table 5. Intensity of suicide ideas in patients who have had suicidal ideation

\begin{tabular}{lcc}
\hline Intensnity of Idea & Frequency & Total (\%) \\
\hline Very Low & 0 & 0 \\
Low & 5 & 45.5 \\
Moderate & 5 & 45.5 \\
High & 1 & 9.1 \\
Very High & 0 & 0 \\
\hline Total & 11 & 100 \\
\hline
\end{tabular}

In Table 5, there are results of the intensity of suicide ideas in patients who have them. The intensity of the idea is derived from the sum of the values of the frequency, duration, control, prevention and reason. There were 5 patients with low intensity (5-10) and moderate (11-15), and 1 person with high intensity (15-20).
Table 6. Suicide attempts in patients who had suicidal ideation

\begin{tabular}{lcc}
\hline Suicide Attempts & Frequency & Total $(\%)$ \\
\hline Yes & 2 & 18.2 \\
No & 9 & 81.8 \\
\hline Total & 11 & 100 \\
\hline
\end{tabular}

Table 6 shows the number of patients who once have an idea of killing and committing suicide experiments. Patients who had attempted suicide were 2 or $18.2 \%$, and who had never attempted to commit suicide amounted to 9 people or $81.8 \%$.

\section{Discussion}

11 patients, or $31.4 \%$, had a suicide idea, and 24 people or $68.6 \%$ never had a suicide idea. The idea of suicide found consisted of 1 person with a desire to die, 1 person with an idea of suicide without a desire to die, and 9 people with both.

The average length of illness in patients who had suicidal ideation was 16.55 years with a deviation standard of 12.941. Patients with schizophrenia have an average length of the pain of 17.73 years with a standard deviation of $9.4 .^{6}$ This research has some similarities with previous research, namely the average length of pain that has an idea of suicide is 16.55 years but has a difference in the standard deviation so that it does not get the absolute conformity. The study cannot conclude the correlation between length of illness and suicide because there is research that the longer the illness time is, the higher the risk factors are. There is also proof that the shorter the pain time is, the higher the risk factors are. ${ }^{7}$

In its diagnoses, the proportion of schizophrenia patients who had an idea of suicide as much as 8 out of 29 people or $27 \%$ and in the affective disorder or bipolar affective Disorder $100 \%$ are 2 of 2 recorded people (Table $3)$. The affective disorder or bipolar affective disorder is called the highest risk diagnosis, especially in developed countries, and occupies the second position in developing countries after impulse-control disorder. ${ }^{8}$ In schizophrenia with paranoid symptoms and hallucinations, there was an increased risk of suicidal ideation. ${ }^{9}$ Severe depression increased the risk of suicide. ${ }^{10}$ However, in this study, the patient suffered mild depression, so there was no history of suicidal ideation.

The current GAF Scale in patients with suicidal ideation consisting of 5 people with GAF Scale 60-51, 2 persons with GAF Scale 70-61, and 4 people with GAF Scale 80-71. The current GAF Scale in patients who never had a suicide idea is located in the above 50-41 range. Meanwhile, the GAF Scale of the patient at the time had an idea of suicide entirely less than 60 (Table 4). The low GAF Scale is a risk factor for suicide. ${ }^{11}$ In another study, it was 
mentioned that the average GAF Scale on one who had thoughts and suicidal behavior was 55.9.12 Therefore, the results in this research have conformity with previous studies. According to the results of this study, a GAF Scale increases in the results taken today compared to the GAF Scale when having a suicide idea.

Patients with the most suicidal ideation are found in the adult and senior age groups (Table 3). Patients who had this suicidal ideation were in the adult and young adult's age group with 4 or $36.4 \%$ (Table 4 ) respectively when the suicide idea appeared. Previous research obtained the average age of a person who has thoughts of suicide and suicide behavior aged 35 years old. ${ }^{12}$

Age 35 years old are included in the young adult age group in this study. This discrepancy can be due to the difference in the number of research samples. In other studies, the percentage of the idea of suicide in the age range of 18-22 years old is relatively high, which is $41.35 \% .{ }^{13}$ The age of $18-22$ years old is in the late adolescence category of the study. According to some research, there is conformity with the results in this study.

There was an almost balanced amount between men and women who had suicidal ideation or never had one (Table 3). The number of female patients who had suicidal ideation was little higher than men. In a previously stated study, adult and adolescent women were more dominant to conduct attempted suicide. ${ }^{14}$

Table 3 shows that most patients do not work, only help their families and work in the private field. Moreover, patients who once had a suicide idea were found in civil servants, private workers who only helped the family and did not work. The number of patients working as civil servants was only one person and once had a suicide idea (Table 3 ). In other studies, the prevalence of $6.8 \%$ of suicidal ideation was obtained in people working in the media, and $3.9 \%$ in administrative and office officers, as well as the lowest prevalence on farmers, fishers, and forest workers by $1.3 \% .{ }^{15}$ Civil servants in research could be likened to administrative and office officers in previous research. The numbers of suicidal ideation are pretty high in the group that does not work, ${ }^{16}$ and this statement corresponds to the study results.

The result of such data is that the patient who once had the idea of killing were the ones who have less than 2.5 million IDR as an income or did not get income at all, while in patients who never had a suicide idea, some of them had a reasonably high income. Low income and not earning are risk factors for suicide, especially in men, but can also occur in other individuals. ${ }^{17}$ Patients with 2.5-6 million incomes are mostly the ones who never had a suicide idea. This indicates conformity with previous studies.

The idea of suicide found much more on non-college graduates than college graduates. ${ }^{15}$ Non-college graduates are patients who do not reach education in college, consisting of patients with elementary school education, junior high school education, and senior high school education. In patients who reached college, much more from who never had suicidal ideation than had suicidal ideation. In this study, many suicidal ideations were found in high school graduates due to many of the patients who were high school graduates, and the proportion of high school graduates who had a big suicidal idea was 6 out of 21. Patients who have never had the idea of suicide have graduated with a bachelor's degree or college graduated were more than one who has had a suicide idea.

The intensity assessment of this suicidal ideation was given to patients who once had a suicide idea of eleven people. The intensity of suicide ideas in patients is calculated from the frequency value, duration, control, prevention, and reason. Five patients with low intensity (510) and moderate (11-15) and one person with high intensity (15-20) were obtained. There is a difference in the intensity of suicide ideas due to characteristics differences in each person. ${ }^{13}$ The characteristics are not further researched in this study.

In patients who once have a suicide, ideas are also excavated whether any of them have attempted suicide, and the results (Table 6) showed that two people had done so. The presence of suicidal ideation and psychiatric illness can be a risk factor for suicide experiments. However, not everyone with the same risk factor will commit suicide, mentioned by NIMH (2019) that people who try to commit suicide have different reactions to the occurrence, thinking, and how to decide from people who do not try to commit suicide. ${ }^{18}$ In previous research, $63 \%$ of the samples had suicidal ideation, and $43.6 \%$ of them attempted suicide. ${ }^{10}$ The difference in results in research is due to samples in previous studies had a major depressive episode, and some of them have psychosis symptoms, whereas research rarely obtained patients with major depressive episodes and quite a large number of samples.

\section{Conclusion}

Suicide ideation was mostly found in patients with longer lengths of illness, a lower score on GAF Scale, younger age, women, unemployed (jobless), lower-income or no income at all, and lower education. These patients have a low-moderate intensity of suicide ideation, and only two had a suicide attempt. The patient who never had suicide ideation mostly had a shorter length of illness, higher income, and some of them had higher education. Researchers are hoping that this research can help the hospital provide better service for intensits with mental disorders and educate them about suicide prevention.

\section{CONFLICT OF INTEREST}

The author stated there is no conflict of interest in this study.

\section{REFERENCES}

1. Indonesia KKR. Peran Keluarga Dukung Kesehatan Jiwa Masyarakat, https://www.kemkes.go.id/article/print/161007000 
05/peran-keluarga-dukung-kesehatan-jiwamasyarakat.html (2016, accessed 5 April 2018).

2. Kesehatan BP dan P. Kesehatan Jiwa. In: Riset Kesehatan Dasar. Jakarta: Kementerian Kesehatan Republik Indonesia, 2013.

3. Organization WH. Suicide. World Health Statistics Data Visualizations Dashboard, https://apps.who.int/gho/data/node.sdg.3-4-viz2?lang=en (2015, accessed 23 March 2018).

4. Washington $U$ of. Forefront Suicide Prevention, https://www.washington.edu/research/researchcenters/forefront-suicide-prevention/ accessed 23 March 2018).

5. Stack SJ. Mental Illness and Suicide. In: Cockerham WC, Dingwall R, Quah SR (eds) The Wiley Blackwell Encyclopedia of Health, Illness, Behavior, and Society. Chichester: WileyBlackwell, 2014, pp. 1618-1623.

6. Corigliano V, Comparelli A, Mancinelli I, et al. LongActing Injectable Second-Generation Antipsychotics Improve Negative Symptoms and Suicidal Ideation in Recent Diagnosed Schizophrenia Patients: A 1-Year Follow-up Pilot Study. Schizophr Res Treatment 2018; 2018: 4834135.

7. Hor K, Taylor M. Suicide and Schizophrenia: A Systematic Review of Rates and Risk Factors. J Psychopharmacol 2010; 24: 81-90.

8. Nock MK, Borges G, Bromet EJ, et al. Suicide and Suicidal Behavior. Epidemiol Rev 2008; 30: 133154.

9. Castelein S, Liemburg EJ, de Lange JS, et al. Suicide in Recent Onset Psychosis Revisited: Significant Reduction of Suicide Rate over the Last Two
Decades - A Replication Study of a Dutch Incidence Cohort. PLoS One 2015; 10: e0129263.

10. Salvo L, Ramírez J, Castro A. Risk Factors for Suicide Attempts in People with Depressive Disorders Treated in Secondary Health Care. Rev Med Chil 2019; 147: 181-189.

11. Tillman JG, Clemence AJ, Hopwood CJ, et al. Suicidality in High-Risk Psychiatric Patients: The Contribution of Protective Factors. Psychiatry 2017; 80: 357-373.

12. Ballard ED, Vande Voort JL, Luckenbaugh DA, et al. Acute Risk Factors for Suicide Attempts and Death: Prospective Findings from the STEP-BD Study. Bipolar Disord 2016; 18: 363-372.

13. Pratiwi J, Undarwati A. Suicide Ideation pada Remaja di Kota Semarang. Dev Clin Psychol 2014; 3: 2434.

14. Darré T, Consuela KAC, Saka B, et al. Suicidal Ideation and Suicide Attempts in Subjects Aged 15-19 in Lomé (Togo). BMC Res Notes 2019; 12: 187.

15. Han B, Crosby AE, Ortega LAG, et al. Suicidal Ideation, Suicide Attempt, and Occupations among Employed Adults Aged 18-64years in the United States. Compr Psychiatry 2016; 66: 176-186.

16. Faria M, Santos MR, Sargento $P$, et al. The Role of Social Support in Suicidal Ideation: A Comparison of Employed vs. Unemployed People. J Ment Health 2020; 29: 52-59.

17. O'Rourke MC, Jamil RT, Siddiqui W. Suicide Screening and Prevention. Treasure Island (FL): StatPearls Publishing, 2021.

18. Health $\mathrm{NI}$ of M. Frequently Asked Questions About Suicide,

https://www.nimh.nih.gov/health/publications/suici de-faq (2019, accessed 6 June 2019). 